\title{
Endoscopic balloon dilatation is an effective management strategy for caustic-induced gastric outlet obstruction: a 15-year single center experience
}

다 (i) $(-)$

\author{
Authors

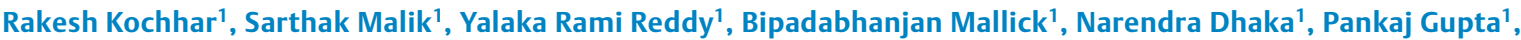 \\ Saroj Kant Sinha', Manish Manrai ${ }^{1}$, Suman Kochhar ${ }^{2}$, Jai D. Wig ${ }^{3}$, Vikas Gupta ${ }^{3}$
}

Institutions

1 Department of Gastroenterology, Postgraduate Institute of Medical Education and Research (PGIMER), Sector 12, Chandigarh 160012, Punjab, India

2 Department of Radiodiagnosis, Government Medical College and Hospital, Sector 32, Chandigarh, Punjab, India

3 Department of Surgery, Postgraduate Institute of Medical Education and Research, Sector 12, Chandigarh 160012, Punjab, India

submitted 16.2.2018

accepted after revision 30.5.2018

Bibliography

DOI https://doi.org/10.1055/a-0655-2057 |

Endoscopy International Open 2019; 07: E53-E61

(c) Georg Thieme Verlag KG Stuttgart · New York

ISSN 2364-3722

Corresponding author

Dr. Rakesh Kochhar, MD DM, Department of

Gastroenterology, PGIMER, Chandigarh - 160012, India

Fax: +91-172-2744401

dr_kochhar@hotmail.com

\section{ABSTRACT}

Background and study aims There is sparse data on the endoscopic management of caustic-induced gastric outlet obstruction (GOO). The present retrospective study aimed to define the response to endoscopic balloon dilatation (EBD) in such patients and their long-term outcome.

Patients and methods The data from symptomatic patients of caustic-induced GOO who underwent EBD at our tertiary care center between January 1999 and June 2014 were retrieved. EBD was performed using wire-guided balloons in an incremental manner. Procedural success and clinical success of EBD were evaluated, including complications and long-term outcome.

Results A total of 138 patients were evaluated of whom 111 underwent EBD (mean age: $30.79 \pm 11.95$ years; 65 male patients; 78 patients with isolated gastric stricture; 33 patients with both esophagus plus gastric stricture). The initial balloon diameter at the start of dilatation, and the last balloon diameter were $9.6 \pm 2.06 \mathrm{~mm}(6-15 \mathrm{~mm})$ and $14.5 \pm 1.6 \mathrm{~mm}(6-15 \mathrm{~mm})$, respectively. Procedural and clinical success was achieved in 95 (85.6\%) and 108 (97.3\%) patients, respectively, requiring a mean (SD) of 5.3 (2.6) and 7.21 (3.86) sessions, respectively. Patients with isolated gastric obstruction had a better response than those with combined esophagus and gastric stricture. Minor complications such as self-limited pain or bleeding were seen in $18(16.2 \%)$ and $16(14.4 \%)$, respectively. Perforation occurred in two patients. Over a follow-up period of 98 months, there were no recurrences.

Conclusion Caustic-induced GOO can be successfully managed using EBD with $97.3 \%$ clinical success.

\section{Introduction}

Cicatrization of the esophagus and stomach is the most common and devastating complication of caustic ingestion [1], with symptomatic esophageal strictures reported to occur in $70-100 \%$ of patients with grade $2 \mathrm{~b} / 3$ injury, and gastric strictures in $30-60 \%$ of individuals [2-6]. Strictures involving the stomach are uncommon due to its large diameter and are usually caused by acids [7]. The most commonly involved site is the antropyloric region, as pooling of the caustic agent occurs in this area and pylorospasm causes prolonged contact with the caustic agent. Surgery forms the cornerstone of the management of caustic-induced gastric outlet obstruction (GOO) and has been advocated by a large number of studies [6,8-10]. However, surgical management has been reported to be associated with serious complications such as pneumonia, 
wound infection, postoperative bleeding, anastomotic breakdown, dumping syndrome, and even death $[6,8,9]$.

There have been many studies on the use of endoscopic balIoon dilatation (EBD) for peptic ulcer related GOO reporting variable success $[11-13]$. In a recent study on the efficacy of EBD for peptic ulcer related GOO, a $95 \%$ success rate was reported [12]. Another study reported symptomatic remission in $100 \%$ of cases [13]. A number of studies have observed that caustic-induced GOO is more difficult to treat than other benign GOO $[14,15]$.

We have previously shown that over $95 \%$ of patients with caustic-induced GOO can be treated effectively using EBD, with an acceptable level of complications [16]. The present study aimed at retrospectively analyzing our database at a tertiary center in north India for all patients with caustic-induced GOO referred to us between 1999 and 2014. This includes some of the patients reported by us in earlier studies $[16,17]$.

\section{Materials and methods}

The records of all of the patients who presented with clinical features of caustic-induced GOO and who underwent EBD in the Department of Gastroenterology, Postgraduate Institute of Medical Education and Research, Chandigarh, India during the study period were retrieved from the endoscopy database and analyzed. Inclusion criteria were: (1) symptomatic GOO with postprandial vomiting and (2) narrowing of the antropyloric area on gastroscopy and barium meal examination. Patients with more than $6 \mathrm{~cm}$ length of esophageal stricture and more than $2.5 \mathrm{~cm}$ of narrowing in the antropyloric area were excluded. The site and length of gastric cicatrization were noted on barium meal films. Informed consent was obtained from each patient at each session, and the study was approved by the Institute's ethics committee.

\section{Procedure}

The patients were requested to fast from midnight on the day before dilatation. Endoscopy was performed to assess residue, and gastric lavage was done before dilatation to remove excess residue for proper visualization of the pyloric opening. Dilatation was carried out using a wire-guided through-the-scope balloon (Achiever, Max Force, or Controlled Radial Expansion balloon; Boston Scientific Corp, Marlborough, Massachusetts, United States), after premedication with intravenous midazolam (Fulsed; Ranbaxy, Mumbai, India) and n-hyoscine butyl bromide (Busopan; Cadila Healthcare, Goa, India) as described earlier [16]. All procedures were performed by the same endoscopist (RK) under endoscopic guidance, and fluoroscopy was used in some patients. The diameter of the balloon was selected on the basis of the endoscopist's subjective assessment of the severity of stenosis and barium findings. The balloon was negotiated across the narrowed segment under endoscopic vision and was positioned approximately equally on either side of the narrowing. The balloon was inflated using a saline solution filled syringe mounted on a pressure gun (Alliance Inflation Device; Boston Scientific Corp) as per the manufacturer's instructions. Balloons of incremental diameter to a maximum of three sizes were used in each sitting, or a controlled radial expansion balloon was inflated to incremental diameters, for 60 seconds at each diameter. Dilatation was repeated at 2- to 3-week intervals. At each dilatation session, the choice of balloon diameter depended upon the patient's symptom response and a rough estimate of the gastric residue at endoscopy. Progressively increasing diameters of balloons were used unless the residue appeared to be the same as on the previous dilatation, in which case the same diameter balloons were used. In patients undergoing early dilatation (less than 3 weeks after caustic ingestion), dilatation was repeated twice a week for the first 3 to 4 dilations, and then every week until clinical success [17]. Patients undergoing dilatation within 3 weeks of caustic ingestion and having active ulcerations were given sucralfate suspension ( $20 \mathrm{~mL}$ every 6 hours p. o.). We do not in principle give proton pump inhibitors to patients with acute/subacute caustic injury [17].

\section{Post-procedure monitoring}

After every dilatation, the area was observed for signs of bleeding, and an attempt was made to negotiate the narrowed segment only if a 12-mm silicon-lubricated balloon had been inflated. Patients were observed for 4 hours after the procedure for pain in the abdomen, tachycardia, or a drop in blood pressure. In cases where there was persistent pain and/or tachycardia, patients were admitted and observed for perforation. In the event of perforation, urgent surgical consultation was taken, and the patient was taken to surgery within 6-12 hours.

\section{Definitions}

Procedural success - Defined as the achievement of $15 \mathrm{~mm}$ dilatation.

Clinical success - Defined as resolution of symptoms of GOO (such as pain in the abdomen, abdominal distension or vomiting) for more than 1 month after the last dilatation with easy passage of a standard gastroscope.

Refractory stricture - Defined as the inability to dilate to a diameter of $15 \mathrm{~mm}$ after five sessions of EBD (modified from Kochman et al. [18]).

Failure - Defined as the inability to achieve clinical success, or the occurrence of any complication requiring surgery.

\section{Dietary advice and counseling}

Only clear liquids were allowed for the first 24 hours after each dilatation. A liquid diet was advised in consultation with a dietician until a dilatation of $10 \mathrm{~mm}$ had been achieved, and then a pureed diet was advocated. Normal diet was permitted after achieving a dilatation diameter of $12 \mathrm{~mm}$.

\section{Adjunctive treatment}

During the last 5 years of the study, patients with refractory strictures were managed with additional measures such as triamcinolone acetonide $(80 \mathrm{mg}$ of Kenacort, Abbott Healthcare Pvt Ltd, India) aqueous suspension, diathermy dilator or a metal stent in some patients as described below. The technique for triamcinolone injection has been described before [19]. Briefly, a 21G sclerotherapy needle was used to inject a 1:1 dilu- 
tion of triamcinolone at 4 quadrants of the rim of the narrowed segment under direct endoscopic visualization. In two patients with esophageal strictures, stents [plastic stent $(n=1)$, biodegradable stent $(n=1)$ ] were used to facilitate passage into the stomach.

\section{Follow-up}

If clinical success was achieved, patients were followed up at 3monthly intervals for 1 year, and then every 6 months for at least 1 year. Patients were assessed for clinical symptoms and an endoscopy was performed at each visit to assess for residue or narrowing.

\section{Statistical analysis}

The data were analyzed using SPSS version 22.0 (SPSS, Chicago, Illinois, United States). During analysis of the data, continuous variables were compared using the Student's $t$ test. Dichotomous variables (e.g. gender) were compared using the Chisquared test. Descriptive statistics were used wherever required. Where appropriate, differences in proportions were assessed using the Chi-squared test. Univariate analysis was performed to identify independent predictors of refractory stricture, and procedural and clinical success. If more than one factor was identified, they were included in a model for multivariate logistic regression analysis backward conditioned to identify independent predictors of refractory stricture, and procedural and clinical success. Other statistical methods were used wherever appropriate. A $P$ value of less than 0.05 was taken to indicate a statistically significant difference.

\section{Results}

- Table 1 gives the patient characteristics. A total of 138 patients were evaluated of whom 111 underwent EBD. The mean age of the patients $( \pm S D)$ was $30.79 \pm 11.95$ years, and there were 65 males and 46 females (1.4:1). The most common caustic agent was an acid, in 99 (89.2\%) patients. Concomitant involvement of the esophagus and stomach was found in 33 $(29.7 \%)$ patients; and $78(70.3 \%)$ patients had isolated GOO. Early initiation of EBD within 3 weeks of caustic ingestion [early dilatation (ED) group] occurred in 33 patients ( $\triangleright$ Fig. 1 ). The parameters assessing response to EBD are given in $>$ Table 2 . Fifteen patients had dilatations initiated with a 6-mm balloon, while the most common starting diameter was $10 \mathrm{~mm}$. The mean \pm SD (range) initial balloon diameter at the start of dilatation, and the last balloon diameter were $9.6 \pm 2.06(6-15) \mathrm{mm}$ and $14.5 \pm 1.6(6-15) \mathrm{mm}$, respectively.

Overall procedural success (balloon diameter of $15 \mathrm{~mm}$ ) was achieved in 95 patients (85.6\%). In three patients, a diameter of $<10 \mathrm{~mm}$ was achieved; all three had complications (perforation, $n=2$; excessive pain, $n=1$ ) and were subjected to surgery. In total, 13 patients achieved a diameter of $12 \mathrm{~mm}$ or $13.5 \mathrm{~mm}$ and had become symptom-free with easy passage of the gastroscope across the antropyloric area. They were not dilated further and did not have any recurrence. Thus, clinical success was achieved in 108 patients (97.3\%) ( $>$ Fig. 2 , $\triangleright$ Fig.3). The
- Table 1 Patient characteristics and demographic details of 111 GOO patients.

\begin{tabular}{l|c|}
\hline Age, mean \pm SD (range), years & $30.79 \pm 11.95(13-67)$ \\
\hline Male/female, $\mathrm{n}(\%)$ & $65(58.6): 46(41.4)$ \\
\hline Corrosive type, $\mathrm{n}(\%)$ & $99(89.2)$ \\
\hline - Acid & $4(3.6)$ \\
\hline - Alkali & $8(7.2)$ \\
\hline - Unknown (? acid/? alkali) & \\
\hline Stricture site, $\mathrm{n}(\%)$ & $33(29.7)$ \\
\hline - Esophagus plus gastric & $78(70.3)$ \\
\hline - Gastric alone & $2.2 \pm 1.5$ \\
\hline $\begin{array}{l}\text { Interval between injury and dilatation, } \\
\text { mean } \pm \text { SD, months }\end{array}$ & \\
\hline & Goo, gastric outlet obstruction; SD, standard deviation. \\
\hline
\end{tabular}

\section{8 patients with caustic GOO evaluated}

27 patients excluded:

1. Long $(>6 \mathrm{~cm})$ esophageal stricture $(n=8)$

2. Esophageal perforation prior to start of gastric dilations $(n=8)$

3. Pyloric stricture more than $2.5 \mathrm{~cm}$ in length $(n=6)$

4. Complete antropyloric obstruction $(n=5)$

\section{1 patients put on dilatation}

Early $n=33$

Late $n=78$

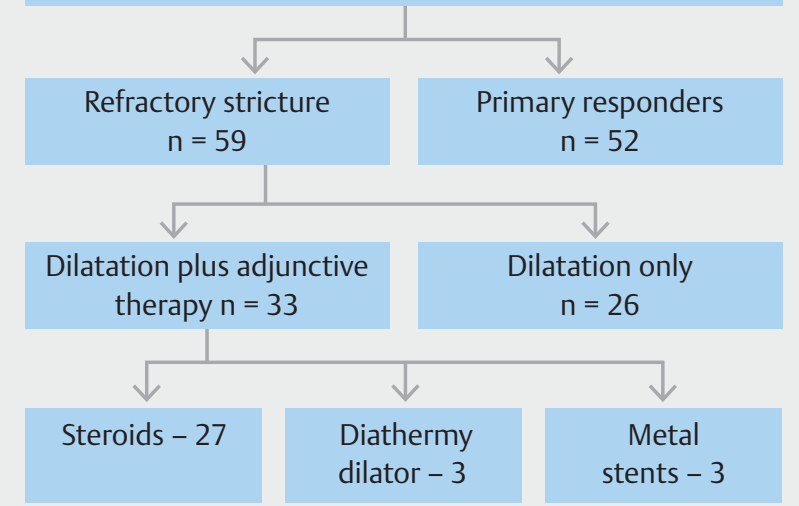

- Fig. 1 Study design.

mean \pm SD (range) number of sessions to achieve clinical success was $7.21 \pm 3.9(1-20)$.

Of the 111 patients, 59 (53\%) were classified as refractory strictures, i. e. those who could not attain a diameter of $15 \mathrm{~mm}$ in 5 sessions of EBD. From 2007 onwards, 27 such patients were also given intralesional triamcinolone during every subsequent dilatation ( $\triangleright$ Fig. 1). When we compared the outcome of these 


\begin{tabular}{|c|c|}
\hline Procedural success, n (\%) & $95(85.6)$ \\
\hline Clinical success, n (\%) & $108(97.3)$ \\
\hline $\begin{array}{l}\text { Number of dilatations to achieve clinical } \\
\text { success, mean } \pm \text { SD (range) }\end{array}$ & $7.21 \pm 3.9(1-20)$ \\
\hline $\begin{array}{l}\text { Number of dilatations to achieve procedural } \\
\text { success mean } \pm \text { SD (range) }\end{array}$ & $5.3 \pm 2.6(1-18)$ \\
\hline \multicolumn{2}{|l|}{ Adjunctive methods to dilatation, n (\%) } \\
\hline - Steroids & $27(24.3)$ \\
\hline - Diathermy dilator & $3(2.7)$ \\
\hline - Esophageal biodegradable stent & $1(0.9)$ \\
\hline - Esophageal plastic stent & $1(0.9)$ \\
\hline $\begin{array}{l}\text { - Pyloric metal stent (WallFlex Biliary RX } \\
\text { Fully Covered Stent System) }\end{array}$ & $2(1.8)$ \\
\hline $\begin{array}{l}\text { - Nagi lumen apposing metal stent } \\
\text { (Taewong Medical) }\end{array}$ & $1(0.9)$ \\
\hline
\end{tabular}

SD, standard deviation; n, number.

27 patients with the remaining 32 patients with refractory strictures who did not receive triamcinolone, we did not find any statistically significant difference in terms of the number of dilatations required to obtain clinical success, and the number of patients achieving procedural or clinical success ( $>$ Table 3).

In three patients, the pylorus was cicatrized to an extent that there was near-total antropyloric obstruction, with no flow of contrast into the duodenum on contrast barium study. We used a hydrophilic 0.025-inch guidewire (Visiglide; Terumo Corp., Shibuyaku, Tokyo, Japan) and a 6-Fr wire-guided coaxial diathermic dilator (Cysto-Gastro-Set; Endo-Flex GmbH, Voerde,
Germany) under fluoroscopic guidance and intermittent diathermy current (cut mode, 40W, ERBE electrosurgical unit (ERBE USA Inc., Marietta, Georgia, United States)) to dilate the tract until it reached the duodenum. All three patients were taken for subsequent dilatation and achieved procedural and clinical success. These three patients have been reported previously [20].

In five patients, self-expandable stents were used. In two patients with isolated $\mathrm{GOO}$, the refractory stricture was treated by placement of a $10 \mathrm{~mm} \times 80 \mathrm{~mm}$ WallFlex Biliary RX Fully Covered Stent System RMV (Boston Scientific Corp., Natick, Massachusetts, United States) across the pyloric stricture. However, in both patients, the stent migrated inwards into the stomach on day 4 and 5 , requiring its removal. In one patient with a refractory antropyloric stricture, an $18 \mathrm{~mm}$ lumen opposing NAGI stent (Taewoong Medical Co, Ilsan, South Korea) was placed but it also migrated back into the stomach on day 7 and was removed. These three patients were continued on dilatation and clinical and procedural success was achieved in all three. In two patients with combined esophagus plus gastric involvement, a plastic stent (Polyflex Esophageal Stent) and a biodegradable stent were used for a refractory esophageal stricture to facilitate pyloric dilatation [21].

In the present study, concomitant involvement of the esophagus and stomach was present in 33 patients (29.7\%). On comparing these patients with the 78 patients having isolated gastric involvement, there was no statistically significant difference in the starting dilatation diameter $(P=0.5)$, or the number of dilatations to achieve procedural success $(P=0.3)$ or clinical success $(P=0.2)$ ( $\triangleright$ Table 4$)$. A greater number of patients with gastric involvement alone attained procedural success $(P=$ $0.01)$; however, there was no statistically significant difference in terms of clinical success $(P=0.4)(\triangleright$ Table 4$)$.

There were 33 patients in the early dilatation (ED) group. We compared the outcome of these patients with those $(n=78)$ who had EBD initiated at least 3 weeks after caustic ingestion
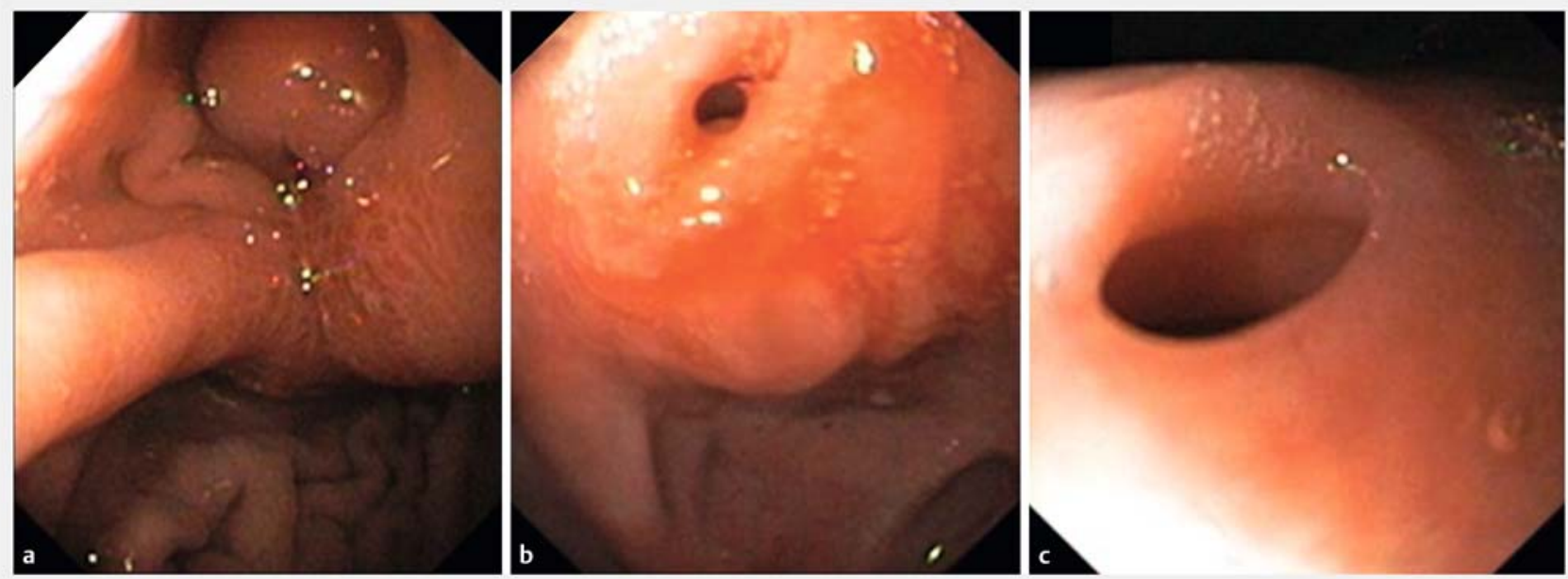

Fig. 2 a Endoscopic view of antropyloric area of a patient around 10 weeks after caustic ingestion showing pinpoint pyloric narrowing. b Endoscopic view of antropyloric area of same patient after two sessions of EBD. c Endoscopic view of antropyloric area of same patient after six sessions of EBD. 

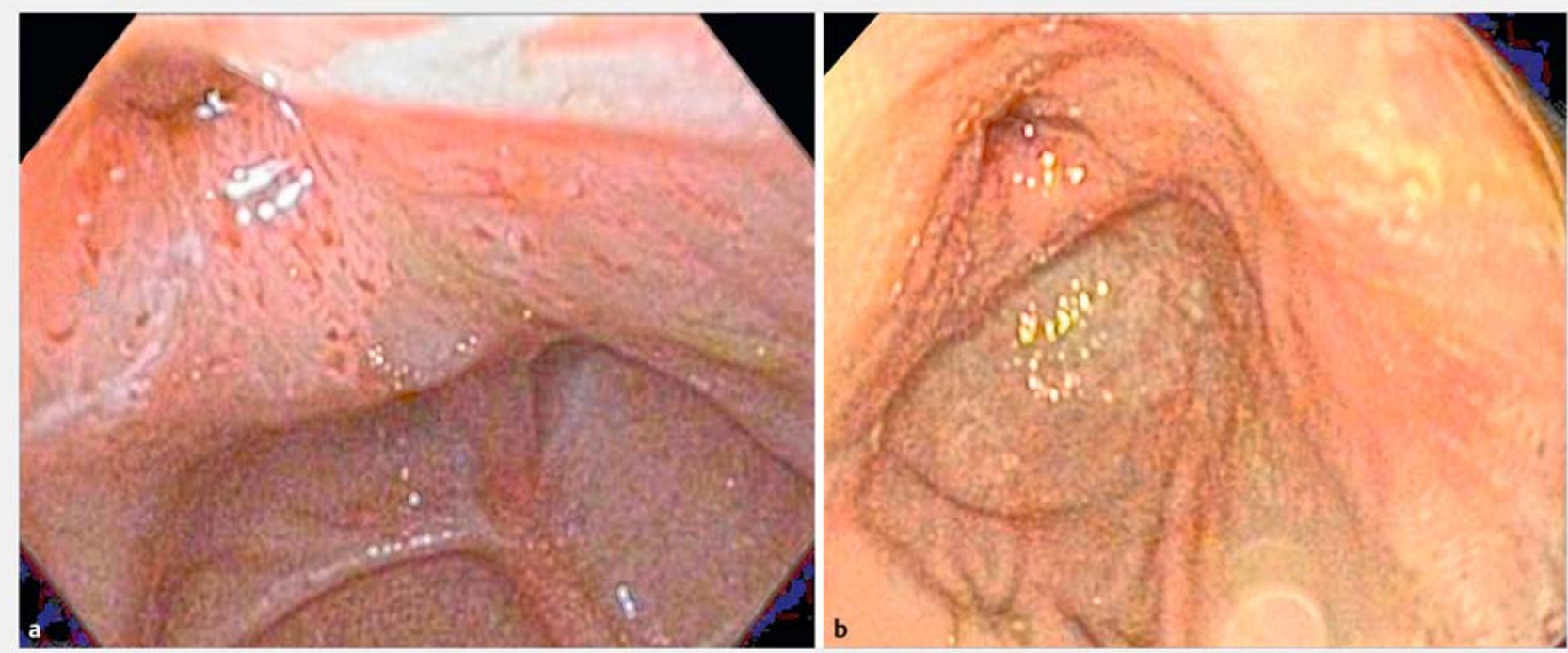

- Fig. 3 a Endoscopic view of antropyloric area of a patient around 8 weeks after caustic ingestion showing eccentric pyloric narrowing at 11 o'clock. b Endoscopic view of clinical success achieved in the same patient, with absence of residue and adequately dilated pyloric opening after five sessions of EBD.

- Table 3 Outcome of patients with refractory strictures given steroids versus those not given steroids.

\begin{tabular}{|l|l|l|}
\hline & $\begin{array}{l}\text { Steroid used } \\
(\mathbf{n = 2 7 )}\end{array}$ & $\begin{array}{l}\text { Steroid not used } \\
(\mathbf{n = 3 2 )}\end{array}$ \\
\hline Number of dilatations to clinical success, mean \pm SD (range) & $8.0 \pm 3.7(2-19)$ & $7.8 \pm 3.2(1-20)$ \\
\hline Balloon treatment duration, mean \pm SD (range), minutes & $4.43 \pm 3.3(1.5-14)$ & $4.2 \pm 3.65(0.5-20)$ \\
\hline Procedural success, $n(\%)$ & $26(96.3 \%)$ & $30(93.8 \%)$ \\
\hline Clinical success, $n(\%)$ & $27(100 \%)$ & $31(96.9 \%)$ \\
\hline SD, standard deviation; $n=$ number of patients. & & 0.9 \\
\hline
\end{tabular}

- Table4 Outcome of patients with endoscopic balloon dilation based on stricture site.

\begin{tabular}{|c|c|c|c|}
\hline & $\begin{array}{l}\text { Esophagus plus gastric stricture } \\
(\mathrm{n}=33)\end{array}$ & $\begin{array}{l}\text { Isolated gastric stricture } \\
(n=78)\end{array}$ & $P$ value \\
\hline Initial balloon size, mean \pm SD (range), $\mathrm{mm}$ & $9.4 \pm 2.1(6-15)$ & $9.6 \pm 2.1(6-15)$ & 0.5 \\
\hline Maximum balloon size, Mean \pm SD (range), $\mathrm{mm}$ & $13.9 \pm 2.3(6-15)$ & $14.8 \pm 1.1(6-15)$ & 0.4 \\
\hline Procedural success, $\mathrm{n}(\%)$ & $24(72.7 \%)$ & $71(91 \%)$ & 0.01 \\
\hline Clinical success, n (\%) & $33(100 \%)$ & $76(97.4 \%)$ & 0.4 \\
\hline Number of dilatations to procedural success, mean \pm SD (range) & $4.8 \pm 2.9(1-12)$ & $5.5 \pm 2.6(1-11)$ & 0.3 \\
\hline Number of dilatations to clinical success, mean \pm SD (range) & $6.4 \pm 4.9(1-20)$ & $7.6 \pm 3.2(1-16)$ & 0.2 \\
\hline
\end{tabular}

[late dilatation (LD) group], and there was no statistically significant difference in procedural or clinical success between the ED versus LD groups ( $\bullet$ Table 5$)$.

\section{Follow-up}

Of the 111 patients, seven patients did not come for follow-up after achieving clinical success. However, they were periodically contacted by telephone and they confirmed the absence of symptoms. The mean \pm SD (range) follow-up period amongst 
- Table 5 Outcome of patients according to time to first dilatation.

\begin{tabular}{|c|c|c|c|}
\hline & $\begin{array}{l}\text { ED group } \\
(n=33)\end{array}$ & $\begin{array}{l}\text { LD group } \\
(n=78)\end{array}$ & $P$ value \\
\hline Time to first dilatation, mean \pm SD (range), days & $19.5 \pm 1.4(16-21)$ & $79.5 \pm 43.2(31-240)$ & 0.02 \\
\hline Number of dilatations, mean \pm SD (range) & $8.3 \pm 3.6(1-20)$ & $6.74 \pm 3.9(1-19)$ & 0.65 \\
\hline Balloon treatment duration, mean \pm SD (range), minutes & $4.73 \pm 4.56(1.5-9)$ & $4.02 \pm 2.9(2-20)$ & 0.21 \\
\hline Procedural success, n (\%) & $31(93.9 \%)$ & $63(80.8 \%)$ & 0.06 \\
\hline Clinical success, n (\%) & $32(96.9 \%)$ & $76(97.4 \%)$ & 0.4 \\
\hline \multicolumn{4}{|l|}{ Complications, n } \\
\hline - Self-limited bleeding/pain & 11 & 23 & \multirow[t]{2}{*}{0.9} \\
\hline - Perforations & 1 & 1 & \\
\hline
\end{tabular}

104 patients available for endoscopic follow-up was $98.59 \pm$ 67.8 months (range 5-230 months). None of the patients had any recurrence.

\section{Complications}

Minor complications such as self-limiting pain and minor bleeding following dilatation occurred in 18 (16.2\%) and 16 (14.4\%) patients, respectively. None of these patients required hospitalization or blood transfusions. Two patients developed severe pain after their first dilatation; however, they were managed conservatively by maintaining nil by mouth and prescribing antibiotics, and they were discharged after 5 days. They were later taken up for dilatation with a gradual increase in balloon size. One patient developed hematemesis after a dilatation, requiring blood transfusion. He was started on dilatation after 2 weeks and achieved clinical success. Two patients developed perforation and severe pain immediately post dilatation. In one patient (ED group) with a refractory stricture, perforation occurred after the 10th dilatation with a $15-\mathrm{mm}$ balloon. The patient did not receive any adjunctive treatment. In the other patient (LD group), perforation occurred in an 18-year-old woman at second dilatation. She underwent first dilatation with an 8-mm balloon. During the second dilatation with a 10$\mathrm{mm}$ balloon, a small tear was visualized through the balloon. The procedure was abandoned, and she underwent surgery 4 hours later, where a 2-mm tear was noted. There was no peritoneal spillage. They both were discharged in a stable condition. One patient underwent four sessions of EBD with severe pain after each session of dilatation and hence opted for surgery. Apart from the above three patients undergoing surgery for perforation and pain, no patient underwent surgery for failure of EBD.

\section{Factors affecting outcome of EBD}

Univariate analysis was performed among age, gender, site of stricture (esophagus plus gastric vs gastric alone), timing of start of dilatation (ED vs LD), and use of steroids to identify factors which could predict procedural success, clinical success, and refractory stricture ( $\triangleright$ Table 6 ). Only the site of stricture emerged as a predictor of better procedural success, as patients with only GOO responded better than patients with combined esophageal and gastric stricture $(P=0.01)$. However, none of the factors evaluated could predict clinical success or refractory stricture ( $\triangleright$ Table 6$)$.

\section{Discussion}

We observed that in 111 patients with caustic-induced GOO treated with EBD, clinical success was achieved in $97.3 \%$ of patients, requiring a mean \pm SD (range) of $7.21 \pm 3.9(1-20)$ sessions of dilatation. These data are in accordance with that of other workers $[14,15,22]$. Caustic-induced GOO has been observed to be more difficult to treat than other benign causes, requiring a greater number of dilatations. Some earlier reports had indicated a high failure rate of EBD in caustic-induced GOO $[15,23]$, but our previous $[16,17]$ and present data support EBD as the first-line treatment of caustic-induced GOO, albeit in patients with a stricture length of less than $2.5 \mathrm{~cm}$.

The end point for dilatation of GOO has not been clearly defined. While most workers have used the same end point $(15 \mathrm{~mm})$ as for esophageal dilatation [14, 24], others have dilated up to $16-18 \mathrm{~mm}$ [15]. Complications such as bleeding and perforation were more frequent if the target dilatation was more than $15 \mathrm{~mm}$ [15]. When we used an end point of $15 \mathrm{~mm}$ (procedural success), we had 13 patients who did not achieve this, yet had resolution of their symptoms. Thus, our procedural success rate $(85.6 \%)$ was lower than the clinical success rate (97.3\%). Generally, the end point of pyloric dilatation has been $15 \mathrm{~mm}$ in all of the previous studies. This end point had been adopted from data on esophageal dilatation [18]. However, our data shows that patients may become symptom-free before achieving a dilatation of $15 \mathrm{~mm}$. Resolution of symptoms is a more relevant end point. Therefore, our data indicate that there is a need to change the end point of pyloric dilatation from a predefined diameter of $15 \mathrm{~mm}$ for clinical success. Moreover, unlike esophageal strictures, the endoscopist can also assess the response to dilatation from the amount of food residue present at the time of dilatation. 
- Table6 Univariate analysis for factors affecting outcome of EBD.

\begin{tabular}{|c|c|c|c|c|c|c|}
\hline Factor assessed & Procedural success & $P$ value & Clinical success & $P$ value & Refractory stricture & $P$ value \\
\hline \multicolumn{7}{|l|}{ Age, mean $\pm S D$, years } \\
\hline - Yes & $30.3 \pm 12.4$ & \multirow[t]{2}{*}{0.7} & $30.6 \pm 12.3$ & \multirow[t]{2}{*}{0.4} & $29.6 \pm 12.2$ & \multirow[t]{2}{*}{0.6} \\
\hline - No & $31.6 \pm 12.1$ & & $23.5 \pm 2.1$ & & $30.9 \pm 12.3$ & \\
\hline \multicolumn{7}{|l|}{ Sex, n (\%) } \\
\hline - Male & $53(81.5)$ & \multirow[t]{2}{*}{0.4} & $64(98.4)$ & \multirow[t]{2}{*}{0.2} & $33(50.7)$ & \multirow[t]{2}{*}{0.7} \\
\hline - Female & $41(89.1)$ & & $44(95.6)$ & & $26(56.5)$ & \\
\hline \multicolumn{7}{|l|}{ Site of stricture, n (\%) } \\
\hline - Esophagus plus gastric & $24(72.7)$ & \multirow[t]{2}{*}{0.01} & $33(100)$ & \multirow[t]{2}{*}{0.4} & $14(42.4)$ & \multirow[t]{2}{*}{0.1} \\
\hline - Gastric alone & $71(91)$ & & $76(97.4)$ & & $45(57.6)$ & \\
\hline \multicolumn{7}{|l|}{ Time of dilatation, $\mathrm{n}(\%)$} \\
\hline - Early dilatation & $31(93.9)$ & \multirow[t]{2}{*}{0.06} & $32(96.9)$ & \multirow[t]{2}{*}{0.4} & $21(63.6)$ & \multirow[t]{2}{*}{0.6} \\
\hline - Late dilatation & $63(80.8)$ & & $76(97.4)$ & & $38(48.7)$ & \\
\hline \multicolumn{7}{|l|}{ Steroid use, n (\%) } \\
\hline - Yes & $26(96.3)$ & \multirow[t]{2}{*}{0.3} & $26(96.3)$ & \multirow[t]{2}{*}{0.9} & NA & \\
\hline - No & $69(82.1)$ & & $82(97.6)$ & & & \\
\hline
\end{tabular}

Solt et al. had also used the same outcome measure [23]. It thus seems that the realistic end point of pyloric dilatation should be 'clinical success'. We believe that caustic-induced esophageal strictures and antropyloric strictures behave differently with a much better response of the latter to endoscopic dilatation.

About one-third to one-half of patients with caustic-induced GOO also have esophageal strictures making the dilatation procedure more complicated, even more so as the diameters of the two strictures may be different. This calls for careful assessment of the stricture length and diameter so that the appropriate balloon can be selected. In such patients, bougie dilators are not recommended for dilating esophageal strictures. The data with regard to the management of combined esophageal and gastric strictures caused by caustic injury is scanty. Chiu et al. reported the results of EBD in 36 patients with caustic injury, of which 11 patients had combined esophageal plus gastric involvement. In their study, the success rates for EBD for GOO alone and combined esophageal plus GOO were $57.1 \%$ and $36.4 \%$, respectively [22]. We also noted a higher procedural success rate with EBD for caustic-induced GOO alone (91\%) versus combined esophageal plus gastric involvement $(72.7 \%, P=$ $0.01)$.

Conventionally, dilatation for caustic-induced esophageal and pyloric stenosis is started 4 to 6 weeks after caustic ingestion. We had 33 patients in the ED group with dilatation commencing within 3 weeks after caustic ingestion. Such patients have associated ulceration and require more frequent dilatation early on [17]. When we compared these 33 patients with the LD group, in whom dilatation was begun at least 3 weeks after caustic ingestion, we noted that the former required a greater number of dilatations to reach $15 \mathrm{~mm}$, although clinical success was similar.

We found that 59 (53\%) of our patients failed to achieve a diameter of $15 \mathrm{~mm}$ in 5 sessions of dilatation. Such patients were classified as "refractory", using the definition of Kochman et al. [18]. We have previously reported the use of intralesional triamcinolone in the treatment of benign esophageal and caustic-induced pyloric strictures with good outcome [19, 25, 26]. From 2007 onwards, 27 such "refractory" patients were treated with intralesional steroids. When we compared patients with refractory stricture in whom intralesional steroids were used to those where steroids were not used, there was no statistically significant difference in the number of dilatations needed to achieve procedural or clinical success. However, a randomized control trial is needed to truly assess the efficacy of intralesional steroids for management of caustic-induced GOO. It is often difficult to target steroid injections in pyloric stenosis because of an often-eccentric pyloric opening and a proximal dilated stomach.

Boron et al. and Hagiwara et al. used electrosurgical incision with a sphincterotome or needle-knife radial incisions combined with balloon dilatation in patients with refractory pyloric stenosis $[27,28]$. The use of a diathermy dilator by the present authors in three patients for almost total occlusion of a pyloric opening has been published previously [20]. This technique can be used in selected patients who have near complete stenosis, and requires very careful use of the cystotome, with a millimeter by millimeter advancement of the accessory to negotiate the narrowed segment. Once a guidewire is in place, dilatation 
can begin. In three of our patients, we used metal stents. In two, a $10-\mathrm{mm}$ biliary metal stent was used and in the third patient, a lumen apposing 18-mm metal stent was used; however, all three stents migrated inwards within 7 days. On the other hand, there are two reports of a good response to a large diameter metal stent in around 30 patients [29, 30]. However, these reports also had migration rates of up to $68 \%$. It should be noted that none of the patients in these two reports had causticinduced GOO.

Complications of EBD include pain, bleeding and perforation. Perforation has been reported to occur in $0-8 \%$ of cases $[11,31,32]$. Larger balloon diameters might be responsible for perforations in previous studies [31,32]. Recent studies of EBD in caustic-induced $\mathrm{GOO}$ report a low perforation rate between $2 \%$ and $4 \%[16,17]$. In the present study, minor complications such as self-limiting pain and minor bleeding following dilatation occurred in 18 (16.2\%) and $16(14.4 \%)$ patients, respectively, and were managed successfully. Two (1.8\%) patients had perforations; both underwent surgery and had an uneventful post-operative recovery. One patient had excessive pain after every dilatation and she opted for surgery.

The strengths of the current study include a large number of patients with caustic-induced GOO, with more than two-thirds having isolated GOO, an entity rarely reported in the literature. The high clinical success rate in the current study was probably due to our meticulous schedule, a single endoscopist (RK) performing all of the procedures, appropriate dietary and nutritional advice, and counseling of patients. After achieving clinical success, all but seven of the patients in the current study were followed up every 6 months with the mean duration of follow-up being 98.6 months. To the best of our knowledge, this is the longest follow-up described in the literature for patients with caustic-induced GOO managed successfully with EBD. The limitations of our study include its retrospective nature and referral bias. The study included only patients with short, isolated antropyloric strictures, which is a select group. The dilatations were performed under endoscopic vision, and fluoroscopy was not used apart from in some patients in the early dilatation group. We used intralesional steroids in 27 of the refractory strictures in the last 5 years of the study; however, it would have been ideal to have randomized such patients. Future studies are warranted to examine the efficacy of steroids.

To conclude, in the largest study to date, we have shown that EBD can successfully ameliorate symptoms in patients with caustic-induced GOO, thereby avoiding surgery in most of the patients. EBD should therefore be the mainstay of management in such patients.

Competing interests

None
References

[1] Contini S, Scarpignato C. Caustic injury of the upper gastrointestinal tract: a comprehensive review. World J Gastroenterol 2013; 19: $3918-3930$

[2] Baskin D, Urganci N, Abbasoglu L et al. A standardised protocol for the acute management of corrosive ingestion in children. Pediatr Surg Int 2004; 20: $824-828$

[3] Ciftci AO, Senocak ME, Buyukpamukcu N et al. Gastric outlet obstruction due to corrosive ingestion: incidence and outcome. Pediatr Surg Int 1999; 15: 88 - 91

[4] Kay M, Wyllie R. Caustic ingestions in children. Curr Opin Pediatr 2009; 21: 651-654

[5] Zargar SA, Kochhar R, Mehta S et al. The role of fiberoptic endoscopy in the management of corrosive ingestion and modified endoscopic classification of burns. Gastrointest Endosc 1991; 37: 165- 169

[6] Gupta V, Wig JD, Kochhar R et al. Surgical management of gastric cicatrisation resulting from corrosive ingestion. Int J Surg 2009; 7: 257-261

[7] Ananthakrishnan N, Parthasarathy G, Kate V. Chronic corrosive injuries of the stomach - a single unit experience of 109 patients over thirty years. World J Surg 2010; 34: $758-764$

[8] Ray D, Chattopadhyay G. Surgical management of gastric outlet obstruction due to corrosive injury. Indian J Surg 2015; 77: 662 - 665

[9] Tseng YL, Wu MH, Lin MY et al. Early surgical correction for isolated gastric stricture following acid corrosion injury. Dig Surg 2002; 19 : $276-280$

[10] Hsu CP, Chen CY, Hsu NY et al. Surgical treatment and its long-term result for caustic-induced prepyloric obstruction. Eur J Surg 1997; 163: $275-279$

[11] Kozarek RA, Botoman VA, Patterson DJ. Long-term follow-up in patients who have undergone balloon dilation for gastric outlet obstruction. Gastrointest Endosc 1990; 36: 558- 561

[12] Hamzaoui L, Bouassida M, Ben Mansourl et al. Balloon dilatation in patients with gastric outlet obstruction related to peptic ulcer disease. Arab J Gastroenterol 2015; 16: 121 - 124

[13] Cherian PT, Cherian S, Singh P. Long-term follow-up of patients with gastric outlet obstruction related to peptic ulcer disease treated with endoscopic balloon dilatation and drug therapy. Gastrointest Endosc 2007; 66: $491-497$

[14] Rana SS, Bhasin DK, Chandail VS et al. Endoscopic balloon dilatation without fluoroscopy for treating gastric outlet obstruction because of benign etiologies. Surg Endosc 2011; 25: 1579-1584

[15] Maharshi S, Puri AS, Sachdeva S et al. Aetiological spectrum of benign gastric outlet obstruction in India: new trends. Trop Doct 2016; 46: $186-191$

[16] Kochhar R, Dutta U, Sethy PK et al. Endoscopic balloon dilation in caustic-induced chronic gastric outlet obstruction. Gastrointest Endosc 2009; 69: 800-805

[17] Kochhar R, Poornachandra KS, Dutta U et al. Early endoscopic balloon dilation in caustic-induced gastric injury. Gastrointest Endosc 2010; 71: $737-744$

[18] Kochman ML, McClave SA, Boyce HW. The refractory and the recurrent esophageal stricture: a definition. Gastrointest Endosc 2005; 62: $474-475$

[19] Kochhar R, Ray JD, Sriram PV et al. Intralesional steroids augment the effects of endoscopic dilation in corrosive esophageal strictures. Gastrointest Endosc 1999; 49: 509-513

[20] Siddappa P, Reddy YR, Gupta P et al. Application of a diathermic dilator for negotiating near-total antropyloric strictures. Endoscopy 2016; 48: E365-E366 
[21] Kochhar R, Samanta J, Basha J et al. Biodegradable stents for caustic esophageal strictures: Do they work? Dysphagia 2017; 32: 575-582

[22] Chiu YC, Liang CM, Tam W et al. The effects of endoscopic-guided balloon dilations in esophageal and gastric strictures caused by corrosive injuries. BMC Gastroenterol 2013; 13: 99

[23] Solt J, Bajor J, Szabo M et al. Long-term results of balloon catheter dilation for benign gastric outlet stenosis. Endoscopy 2003; 35: 490 495

[24] Boylan J], Gradzka MI. Long-term results of endoscopic balloon dilatation for gastric outlet obstruction. Dig Dis Sci 1999; 44: 1883-1886

[25] Kochhar R, Sriram PV, Ray JD et al. Intralesional steroid injections for corrosive induced pyloric stenosis. Endoscopy 1998; 30: 734-736

[26] Kochhar R, Makharia GK. Usefulness of intralesional triamcinolone in treatment of benign esophageal strictures. Gastrointest Endosc 2002; 56: $829-834$

[27] Hagiwara A, Sonoyama Y, Togawa T et al. Combined use of electrosurgical incisions and balloon dilatation for the treatment of refrac- tory postoperative pyloric stenosis. Gastrointest Endosc 2001; 53 : $504-508$

[28] Boron B, Gross KR. Successful dilatation of pyloric stricture resistant to balloon dilatation with electrocautery using a sphinctertome. J Clin Gastroenterol 1996; 23: 239-241

[29] Choi WJ, Park J], Park J et al. Effects of the temporary placement of a self-expandable metallic stent in benign pyloric stenosis. Gut Liver 2013; 7: $417-422$

[30] Heo J, Jung MK. Safety and efficacy of a partially covered self-expandable metal stent in benign pyloric obstruction. World J Gastroenterol 2014; 20: 16721 - 16725

[31] Lau JY, Chung SC, Sung J] et al. Through-the-scope balloon dilation for pyloric stenosis: long-term results. Gastrointest Endosc 1996; 43: $98-101$

[32] Lam YH, Lau JY, Fung TM et al. Endoscopic balloon dilation for benign gastric outlet obstruction with or without Helicobacter pylori infection. Gastrointest Endosc 2004; 60: 229-233 